Arteterapia. Papeles de arteterapia y educación para inclusión social ISSN-e 1988-8309

http://dx.doi.org/10.5209/ARTE.59855

\title{
Cómo construirse un hombre. Un caso clínico de arteterapia con un joven con síndrome de Down y conflicto en la identidad de género ${ }^{1}$.
}

\author{
Eva Cristina Mesas Escobar ${ }^{2}$
}

Recibido: 10 de marzo de 2018 / Aceptado: 14 de julio de 2018

Resumen. El presente artículo presenta una experiencia de arteterapia con un joven con síndrome de Down, que manifiesta, desde su adolescencia, crisis de identidad de género. Partiendo de las teorías de Donald Winnicott sobre el desarrollo del sentido de la identidad en el sujeto, comenzamos exponiendo un cuerpo teórico, que permita al lector entender la difícil construcción de la identidad y el falso self, en las personas con discapacidad intelectual.

En el análisis de caso clínico, podemos observar cómo el paciente puede ir dando forma a todo aquello que permanece indefinido en su interior, construyendo una imagen de sí mismo. Trabajamos juntos en la compleja búsqueda de la propia identidad, que le permitiera adueñarse definitivamente de un género que continúa en proceso. En el recorrido de las sesiones, el paciente ha podido conquistar espacios propios, establecer puentes de acceso con lo subjetivo, apropiarse de su pensamiento y encontrar una representación subjetiva de sí mismo: un modo singular par ser y presentarse a los otros.

Palabras clave: Arteterapia; síndrome de Down; Discapacidad intelectual. Subjetividad. Construcción de la identidad; Identidad de género.

\begin{abstract}
This article presents an art therapy experience with a young man with Down syndrome, who manifests, from his adolescence, gender identity crisis. Starting from the theories of Donald Winnicott on the development of the sense of identity in the subject, we begin by exposing a theoretical body, which allows the reader to understand the difficult construction of identity and the false self in people with intellectual disabilities.

In the clinical case analysis, we can observe how the patient can give shape to everything that remains undefined inside, building an image of himself. We work together in the complex search of our own identity, which allows us to take over a genre that continues in process. In the course of the sessions, the patient has been able to conquer their own spaces and establish access bridges with the subjective, in addition to appropriating their thinking and finding a subjective representation of himself: a unique way to be and present himslef to others.
\end{abstract}

Keywords: Art therapy; Down syndrome; Intellectual disability. Subjectivity. Identity construction; gender identity.

Sumario. 1. Introducción 2. La difícil construcción de la identidad y falso self en la persona con discapacidad. 3. Presentación del caso. 4. Primeras sesiones. 5. Proteger mi isla: Un lugar para vivir 6.Construirse un hombre. 7. Conclusiones. 8. Referencias Bibliográficas.

1 Grupo de investigación: Prácticas artísticas y ciudadanía. Universidad de Murcia

2 Licenciada en Bellas Artes. Docente en el Máster de arteterapia de la Universidad de Murcia y Universidad Politécnica de Valencia. Arteterapeuta con personas con síndrome de Down. Centro de Estudios en terapias creativas. Universidad de Murcia.

evamesas@msn.com 
Cómo citar: Mesas Escobar, E.C. (2018). Cómo construirse un hombre. Un caso clínico de arteterapia con un joven con síndrome de Down y conflicto en la identidad de género, en Arteterapia. Papeles de arteterapia y educación para inclusión social 13, 2018, 33-52.

\section{Introducción}

El proceso de creación y transformación de la materia en los talleres de arteterapia ofrece al sujeto la posibilidad de recuperar contenidos y significantes conscientes e inconscientes, de elaborar símbolos y relacionar nuevos contenidos y significados; en definitiva: construir pensamiento. La creación, a través de un profundo diálogo interior, permite dar forma y color a aquello que permanece informe e indefinido dentro de uno mismo. Y es así, desde este complejo proceso, como surge la imagen, en ocasiones, como respuesta a un conflicto.

La imagen realizada en arteterapia encarna pensamientos y sentimientos, es mediadora entre el inconsciente y nuestros pensamientos conscientes, sostiene y simboliza aspectos pasados y presentes de la persona que la ha realizado y actúa como un puente entre el mundo interior y la realidad externa, que ayuda a significar y elaborar contenidos confusos. (Dalley \& Casey: 1992: 69-70). Según la psicoanalista Lola López Modéjar: "el proceso de creación está relacionado con la capacidad de comunicarse con las capas más primitivas del inconsciente, con estas experiencias somáticas primitivas que luego se unirán a representaciones de la palabra" (2009: 21).

La atribución de la identidad de género representa el momento en que cada persona se autodefine como de un género u otro. Este proceso es dinámico y los conflictos aparecen cuando el género al que la persona siente pertenecer no coincide con el que le fue asignado en el momento de su nacimiento, lo que se conoce como Disforia de Género. Entendemos la identidad de género como un proceso de construcción psíquica, donde intervienen la construcción de la imagen del cuerpo, el desarrollo subjetivo e intersubjetivo. En definitiva como un proceso unido a la identidad del yo.

Es fácil imaginar que la identidad del yo en la discapacidad es un espacio débil, un lugar continuamente asaltado y despojado por los otros significantes. El trabajo plástico desde la arteterapia ofrece a la persona con discapacidad la posibilidad de acceder a un espacio protegido, de apuntalar puntos de sujeción en lo más propio de sí mismo, establecer anclajes con los subjetivo, que aunque débiles, le transportan a un lugar seguro: aquel que sostiene la propia creación.

\section{La difícil construcción de la identidad y el falso self en las personas con discapacidad intelectual}

Para entender la dificultad de la construcción de la identidad en las personas con discapacidad intelectual, es necesario atender cómo se estructura, en términos generales, la formación del yo y el desarrollo de la identidad en el sujeto.

Para ello, traemos los condicionamientos teóricos del pediatra y psicoanalista Donald Winnicott, el cual plantea una diferenciación entre el nacimiento biológico y el nacimiento psicológico del individuo. Como sabemos, el nacimiento biológico es un acontecimiento preciso y objetivo, mientras que el nacimiento psicológico se 
formularía como un proceso intra-psíquico, progresivo y gradual, que analizaremos a continuación.

La paradoja fundamental del autor es formular que el bebé no existe, lo que existe es la pareja de crianza. (Winnicott, 1964). Esta fórmula parte de la idea de que, en un primer momento, el bebé no existe como un ser separado sino, únicamente, en una relación simbiótica con la madre. A través de los cuidados primarios de la madre satisfactoria o buena, el bebé es capaz de vivir una experiencia de omnipotencia, sentirse creador de ese objeto que le satisface, imaginando que no es la madre sino él mismo quién satisface mágicamente sus necesidades. (Winnicott, 1962: 66).

La madre no debe ser siempre buena, sino suficientemente buena, factor necesario para que esta vaya introduciendo progresivamente fallas en sus funciones maternas, que van a introducir el principio de realidad en el niño, iniciando un proceso de separación madre-hijo. En este proceso de separación el bebé comienza a tener conciencia de estar separado de la madre. Se da, entonces, el primer contacto objeto de amor para el niño, que sería el rostro de la madre, por primera separada de él. Según Winnicott, en el momento de separación de la madre e individualización del sujeto, tendría lugar el nacimiento psicológico del infante: escenario en que el bebé sale de una dependencia absoluta de la madre a una independencia relativa. (1963: 307-324).

La madre, el primer objeto de amor del bebé, debe reflejar el gesto espontáneo del bebé y consagrarlo. Para que éste, al mirarse en los ojos de su madre, pueda verse a sí mismo. Si la conexión madre e hijo es perfecta y no perturbada se presentan las bases de la empatía y de toda la profunda conexión madre-hijo posterior. Si por alguna razón la madre no refleja en el niño una imagen agradable de sí mismo (madre depresiva, ausente o desilusionada), el bebé experimenta el trauma de estar expuesto al no-yo, a no poder reconocer una imagen de sí mismo, lo que dificulta el desarrollo madurativo y la posterior identidad del yo.

Ya hemos dicho que la madre, separada de sí mismo, constituye el primer objeto de amor para el niño, abriendo camino a otros objetos de interacción, a través de los cuales se va haciendo la vida psicológica del sujeto y la aparición del pensamiento. El objeto transicional sería la primera posesión del bebé (una mantita, un osito, etc.), que el bebé crea para simbolizar a la madre cuando esta no está. Winnicott nos dice que este objeto se construye en un espacio transicional, en una zona intermedia entre lo subjetivo y lo objetivo: la zona que da lugar a la creatividad (Winicott, 1971: 82). El niño utiliza este espacio y los objetos transicionales para hacer frente a la pérdida, construyendo vínculos simbólicos controlables que le ponen en relación con el mundo. En esta zona transicional tiene lugar la individualización del sujeto, que pasa por un proceso de separación del cuerpo de la madre, a través del cual va entrando progresivamente en contacto con su propio cuerpo, desde lo sensorial a lo afectivo-mental, en la apropiación de sus propias experiencias, vivencias en la integración de sus características individuales. La construcción de la subjetividad se da en el marco de confianza con los otros significativos. Los vínculos tempranos, las funciones maternas, y las relaciones con los objetos, adquieren un rol fundamental para pensar la subjetividad, así como para el desarrollo y formación de una identidad de yo. (Winnicott, 1971)

En relación a cómo se da este proceso en las personas con discapacidad, Enrico Montobio, afirma que el momento de la separación de la madre, condición necesaria para el nacimiento psicológico, es especialmente difícil para ellos. Afirma que las 
personas con discapacidad suelen hacer poco uso de los objetos transicionales, y esto provoca que el espacio transicional, ese lugar intermedio entre la fusión y la individualización, permanezca activo durante mucho tiempo, ocupando también su vida adulta (1995: $30-35)$.

Cuando hablamos del éxito de las funciones maternas hacia el desarrollo y la formación de la identidad, resulta necesario aludir a otro concepto, incorporado también por Winnicott, utilizado posteriormente por varios autores, para explicar un tipo de organización psíquica patológica que se observa de manera general en las personas con discapacidad intelectual. Se trata del concepto de falso self, que se opone al concepto de self verdadero (el sí mismo auténtico, como logro de una identidad de yo). Según Winnicott, en condiciones normales, el falso self, ayudaría al sujeto a adaptarse al mundo exterior, y le permitiéndole participar de forma diferente de lo íntimo y de lo social. Sin embargo, en casos patológicos, el falso self neutraliza al verdadero, no permitiendo que el verdadero self (el sí mismo auténtico) pueda desarrollarse en ningún espacio de la vida del sujeto.

En la discapacidad, la dificultad de salir del espacio potencial se debe a un incorrecto entendimiento entre el niño con discapacidad y la madre durante las funciones maternas. Es fácil comprender que en el niño con discapacidad los tiempos de reacción son más lentos respecto a un niño sin discapacidad. En este sentido, cuando la madre sonríe al niño, la respuesta generalmente no es inmediata. Esto hace que la madre pueda interpretar la sonrisa del niño como algo que no ha sido provocado por ella, generando así un vacío en la relación, que no gratifica a la madre ni al niño. Y con frecuencia, la madre deja de responder al gesto del niño. En lugar de una respuesta, la madre coloca en ese lugar su gesto propio, al cual el niño sólo puede responder con sumisión.

Esta sumisión supone el inicio de un falso self en el niño, que en la discapacidad suele aniquilar completamente su verdadero self, dejando poco espacio a la espontaneidad propia del niño; dando lugar a que la imitación de los otros se convierta en su única forma de ser. De esta forma, la persona con discapacidad tiende a modelar su personalidad a semejanza de los otros o según el deseo del otro. Dejando muy poco espacio a su propio deseo de ser: donde la prioridad es ser amado a condición de no ser.

\section{Presentación del caso}

Roberto es un joven de 27 años, con síndrome de Down, que según trasladan los profesionales del centro del día-ocupacional para personas con síndrome de Down al que acude, manifiesta conflicto en la identidad de género desde la adolescencia. Este conflicto se manifiesta en la demanda de ropa y enseres femeninos, así como declarando querer tener pechos y pelo largo, y en la manifestación directa de ser mujer y dirigirse a sí mismo con un nombre en femenino.

En su relación con los demás, observamos que tiende a estar aislado, no relacionándose con los compañeros. Manifiesta no tener amigos y pasar el tiempo sólo en su habitación. No suele hablar con compañeros o monitores por iniciativa propia, aunque es capaz de mantener un diálogo fluido y coherente si es un profesional quien inicia y mantienen la conversación. Presenta buena dicción y expresión verbal, así 
como un lenguaje rico y espontáneo en espacios de contención. Es excesivamente tímido y reservado en espacios públicos.

Destaca en su personalidad una imaginación desbordante y obsesión por las películas fantásticas. En ocasiones, ha manifestado dificultad para discernir su realidad de toda la ficción que consume. Observamos una estructuración correcta de la temporalidad y buena memoria, puesto que es capaz de contar y desarrollar el argumento de una película que ha visto recientemente y prestar atención a gran cantidad de detalles.

En relación a su ambiente familiar, destacaríamos que vive sólo con sus padres en el domicilio familiar. Tiene un hermano mayor independizado al que no refiere nunca en los talleres de arteterapia. Hace referencia, sin embargo, continuamente de forma amorosa a sus tías y su cuñada. Habla de la madre en algunas ocasiones, generalmente con afecto y otras con desafiante oposición. Pero, en pocas ocasionas, refiere al padre de forma individual. De manera general se refiere a sus padres como si se tratara de una institución indivisible.

En relación a la crisis de identidad de género, lo padres cuentan a los profesionales que le permitían a Roberto vestirse de sevillana cuando era niño, ya que le gustaba imitar a cantantes folklóricas, y que solía disfrazarse en eventos familiares, convirtiéndose en el centro de atención. Los padres colocan en este acontecimiento el inicio de su confusión de género.

Con estos datos, y ante la aprobación del equipo técnico al que pertenezco, comenzamos las sesiones individuales de arteterapia en noviembre de 2016, llevando en la actualidad un año y medio de tratamiento, con una periocidad de una hora y media semanal.

\section{Primeras sesiones. En busca de un yo}

Las tres primeras sesiones con Roberto en el taller de arteterapia me sirven de toma de contacto y asesoramiento. Estas primeras sesiones me permiten definir el nivel de intervención del trabajo y los objetivos. Decidimos trabajar, durante un primer año, con un nivel de contención, haciendo muy evidente el mediador artístico en la relación terapéutica, centrándonos en el proceso creativo y trabajando directamente sobre él, con el objetivo principal de propiciar un espacio de contención donde expresar las emociones, sentimientos y sensaciones.

Pactamos con el participante la asistencia al taller y definimos el encuadre de trabajo. Desde el primer día, Roberto se muestra entusiasmado con el taller, le encantan los materiales y sobretodo tener un espacio de atención personalizada. Descubrimos que tiene aptitudes artísticas y, desde niño, le encanta pintar y colorear con rotulador. Observamos que su actitud es mucho más abierta y espontánea en el espacio de taller individualizado que cuando trabaja en grupo.

Durante las primeras sesiones utiliza el lápiz para dibujar. Realiza una primera obra que titula: Yo soy (Fig. 1). Se trata de una figura humana. Me comenta que se está dibujando a sí mismo, trabaja concentrado y tranquilo, hasta que tiene que pintar el rostro y el pelo: entonces, me pide ayuda para dibujar el pelo. Dice:

- Quiero pintar un el pelo, tiene que ser negro y horroroso. El pelo es lo más importante. 


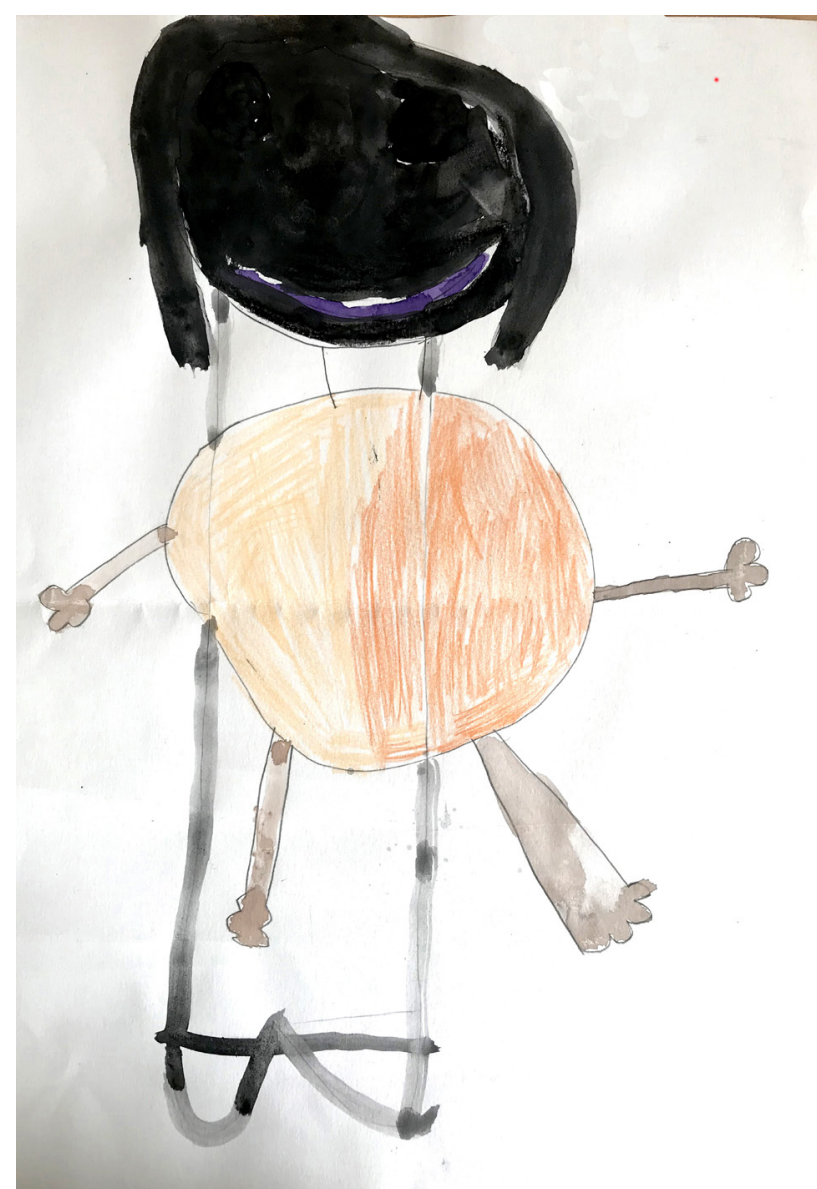

Fig. 1. Título: Yo soy. Dibujo con lápices y acuarelas. Fotografía de la autora.

No consigue hacerlo como él quiere, y se queda bloqueado, borra varias veces el rostro y el pelo y vuelve a dibujarlo sin éxito. Intento ayudarle ofreciendo otros materiales que le estimulen para salir del bloqueo: lanas, acuarelas, papeles. Le propongo alternativas, y finalmente elige las acuarelas, de las cuales utiliza únicamente el color negro.

- Necesito el negro, pintura negra con pintura se quedará horroroso, quiero tapar toda la cara. Así negro todo, así tiene que ser - Expresa Roberto.

Pinta las extremidades con una suave veladura de acuarela negra, y después pinta una y otra vez el rostro hasta que lo deja tan oscuro cómo él desea, cubriendo el rostro de negro en su totalidad. Después repasa con acuarela una forma rectangular que atraviesa el cuerpo. Una vez terminado explica su dibujo:

- Yo soy. Pelo negro, ojos negros, cara negra. El cuerpo desnudo. Yo soy... (hace un pausa) horroroso, todo el mundo me ve horroroso. 
Le devuelvo que yo no le veo horroroso, que él no es horroroso, pero que quizás él ve en sí mismo algo que no le gusta. Me inquieta el rectángulo que atraviesa el cuerpo y le pregunto por él. Primero me responde que no sabe qué es y más tarde me dice que es el cuerpo. Veo entonces que se trata de un retrato con dos cuerpos.

Titula la obra: Yo soy. Este título me hace pensar en Enrico Montobio que parafraseando a D. Winnicott nos dice:

Las palabras más agresivas y por ello las más peligrosas en los lenguajes de todo el mundo las encontramos en la afirmación "Yo Soy". Sin embargo, hay que admitir que sólo los que han alcanzado el estadio que les permite hacer esta afirmación son a pleno título, miembros adultos de la sociedad" (1995:2)

Entiendo que Roberto intenta construir una identidad a través de la realización de un retrato, que todavía no puede afirmar. Resulta demasiado difícil construir una imagen para ese Yo soy. Vemos una figura humana con dos cuerpos: uno redondo, desnudo, carnal y sensible; otro rectangular, transparente, fantasmal, casi invisible. Uno parece ser la sombra o el reflejo del otro, ambos sostienen un rostro cubierto de pintura negra, todavía sin identidad. Todo pareció complicarse cuando Roberto estaba dibujando el pelo, eso sería, tal y como repite textualmente Roberto: lo más importante.

El pelo aparece en varias ocasiones como el foco del conflicto de su identidad de género. Esto nos remonta a la primera etapa de identificación de género, en la que el niño, categoriza el sexo del otro por su aspecto físico, y no por las diferencias sexuales como debería ser. En esta etapa, el pelo es un elemento categorizante de la identidad de género, por el cual se diferencia niños y niñas. En el proceso creativo de Roberto, el pelo se vuelve algo tan importante, que pareciera que de este fuera a depender, única y exclusivamente su identidad, y que de alguna manera sintiera ser hombre o mujer en la medida en que acertara plásticamente en la representación de ese pelo, que al no poder hallar su forma, se vuelve negro y horroroso para él, y "para los otros".

En las siguientes sesiones le invito a dibujar a partir de la silueta de la mano (Fig.2). Contornea su mano y la decora a su gusto. Elige rotuladores, colorea muy despacio. Requiere varias sesiones para colorear minuciosamente todo el trabajo. El proceso es agotador para él y para mí. Le repito que debemos ajustar los tiempos de trabajo a los tiempos del taller, pero cada vez colorea con más minuciosidad, haciendo caso omiso a mis apelaciones. Pinta la mano de color amarillo y el antebrazo de color rosa. Una vez que la obra parecía acabada me dice que va a decorar todo el fondo como si fuera un estampado de lunares, del mismo estampado que una falda de sevillana que él tenía de pequeño.

La recreación y lentitud de Roberto se me hace agotadora en el taller. Pienso que se trata de una provocación. Como si quisiera provocar el cansancio en mí, pero en realidad creo que quiere saber si me cansaré de él, si le sentiré horroroso como manifestaba ser en su anterior obra y le abandonaré, o si permaneceré a su lado en la recreación de su tiempo infinito.

Durante varias sesiones, Roberto ha sabido que he permanecido a su lado, y ahora es él quien no quiere dejarme. Alarga el tiempo de recogida de material y tengo que devolverle varias veces que es la hora. 


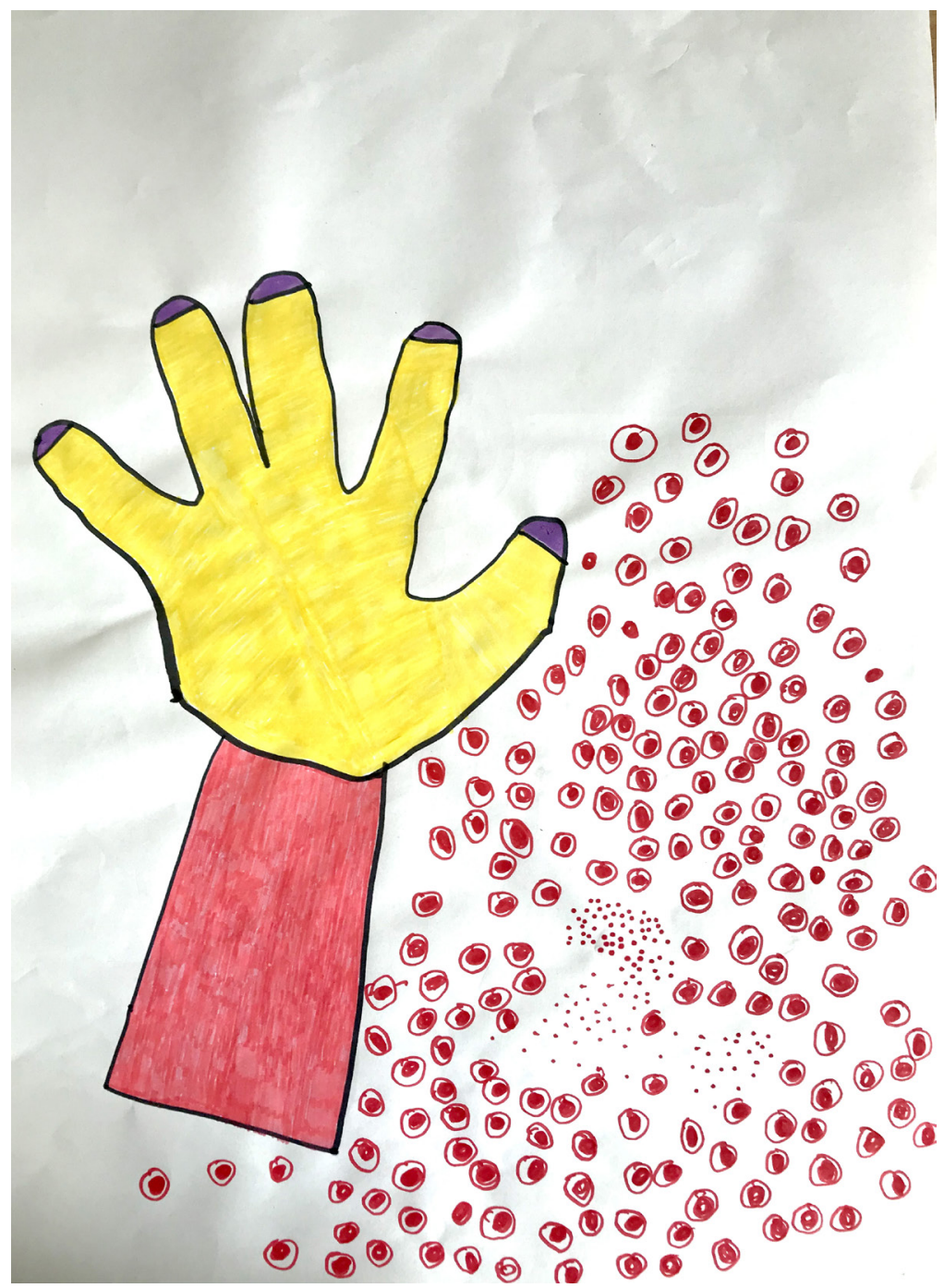

Fig. 2. Título: Mi mano. Dibujo con rotuladores. Fotografía de la autora

- ¿Qué hora es?- Me pregunta.

- Son las 5 en punto. El autobús del centro viene ya-Le respondo.

- Me da mucha pena - me dice- yo me voy y tú te quedas sola, sin hablar con nadie y encerrada en tu habitación. Pobrecita, No te preocupes, mañana te veo y hablo contigo.

Entiendo, en su preocupación, que aunque parezca que lo elige, no le gusta estar sólo. Su actitud es muy diferente dentro y fuera del taller. En el taller se siente seguro, habla, pregunta: es espontáneo. Fuera del taller se siente amenazado por los compañeros, sobre todo por los chicos, y se aísla. Pienso que es fuera del taller donde él está sólo y no habla con nadie. Entiendo que no querer dejarme es no querer dejarse, en realidad: no querer irse. 
Tras varias sesiones, la decoración del fondo de su dibujo se hace agotadora también para él y decide dejarlo. Entonces hablamos de su obra. Me cuenta que la mano es cómo un sentimiento, ya que todas las personas tienen dos manos para acariciar y trabajar. Me dice que es su propia mano, que su mano es áspera de hombre y su brazo es suave como una mujer. Vuelve a mirar el fondo que enmarca la silueta de su mano y los puntos rojos ya no son el estampado de lunares de su falda de sevillana. Ahora se vuelven desagradables, se han convertido en granos. Me dice:

- Todo está lleno de granos con sangre y pus. Yo los estoy tocando y me da mucho asco. Tengo mi mano sucia de sangre y pus.

De nuevo aparece la dualidad, mano y antebrazo diferenciado por colores: hombre y mujer en una única mano. La dualidad hombre/mujer en el proceso de Roberto podría entenderse como un mecanismo de defensa, que entenderíamos como una escisión o disociación, mediante el cual uno puede dividirse y poner en otro lugar en una parte de sí, separando así los aspectos hostiles que no reconoce en sí mismo. La mano que toca y siente es de hombre. Sin embargo, el brazo que dirige esa mano, es de de mujer. Parece que ante esa dualidad se reactiva de nuevo lo horroroso. Lo que toca la mano ya no es agradable: se convierten en pus y sangre, elementos corporales de abyección y expulsión, que parece indicar que existe algo que no quiere, o quizás no debe tocar.

Sigmund Freud afirmó a principio del siglo XX, con gran escándalo en la sociedad de su época, que los niños tienen instintos y deseos sexuales, ya que entendía que estos impulsos sexuales, a los que llamaba libido, iban más allá del propio acto sexual en sí, e incluía las sensaciones de satisfacción y placer que el niño experimentaba realizando diversas actividades (Freud, 1905: 109-222). En sus obra: Tres ensayos sobre la teória sexual, afirmaría que:

El niño es un perverso polimorfo, que disfruta perversamente de todos los orificios de su cuerpo y dirige sus deseos sexuales hacia cualquier objeto, desorganizadamente (por carecer de identidad), y sin represión, lo que le hace carecer de identidad sexual (o de género), identidad personal e incluso de inconsciente. (1905: 173)

Julia Kristeva, siguiendo las teorías sobre la sexualidad infantil de Freud, define en un primer momento, lo abyecto como aquello que se escapa del interior de cuerpo (sangre, excrementos, fluidos corporales, etc...), aquello que forma parte de nuestra propia interioridad, pero que una vez fuera de él se vuelve abyección, repulsión y suciedad. Sin embargo, el niño, ese perverso polimorfo del que hablaba Freud, goza de su interioridad, ya que carece del concepto de abyecto porque su cuerpo continúa profundamente unido al de la madre. Es justamente en el proceso de individualización del cuerpo de la madre, donde se aprende la abyección, y toda esa interioridad de la que antes se gozaba, se vuelve extraña y es expulsada a través del asco. (Kristeva, 1989: 7-47).

El estampado de la falda de sevillana volverá en varias sesiones. Como el pelo, la falda constituye otro de los elementos categorizantes de la identidad de género a edades tempranas. Roberto parece obsesionado con la falda de sevillana que representa 
una y otra vez en el taller (llega a realizar unas diez representaciones de sevillanas con falda de lunares, que van evolucionando, con ligeras variaciones). Recordemos que los padres le permitían disfrazarse de sevillana cuando era pequeño, y cuentan que solía hacer representaciones de Rocío Jurado en las reuniones familiares de las que todos disfrutaban, siendo Roberto el centro de atención.

A mi entender, esa falda marcaría un momento importante en la incorporación de la subjetividad de Roberto, y en su relación con los otros significantes. Parecería que a través de esa falda podía recuperar una imagen de sí mismo que no se completó en sus primeros tiempos en el rostro de la madre. Y que, esta vez, esa falda podía devolverle un lugar seguro donde mirarse: en la mirada gustosa y deseante de los otros significativos. Pero, tal y como observamos en su obra, (Fig. 3) debajo de la falda de sevillana, se manifiesta un yo frágil: un sostenedor vacío, al que Roberto apenas señala con inseguridad en lápiz. Detrás de una elaborada falda de sevillana encontramos un ser con un aspecto fantasmagórico, que parece haber perdido la noción del tiempo y el espacio vividos, y que ha quedado congelado en un espectáculo de Rocío Jurado a la espera de una ovación final.

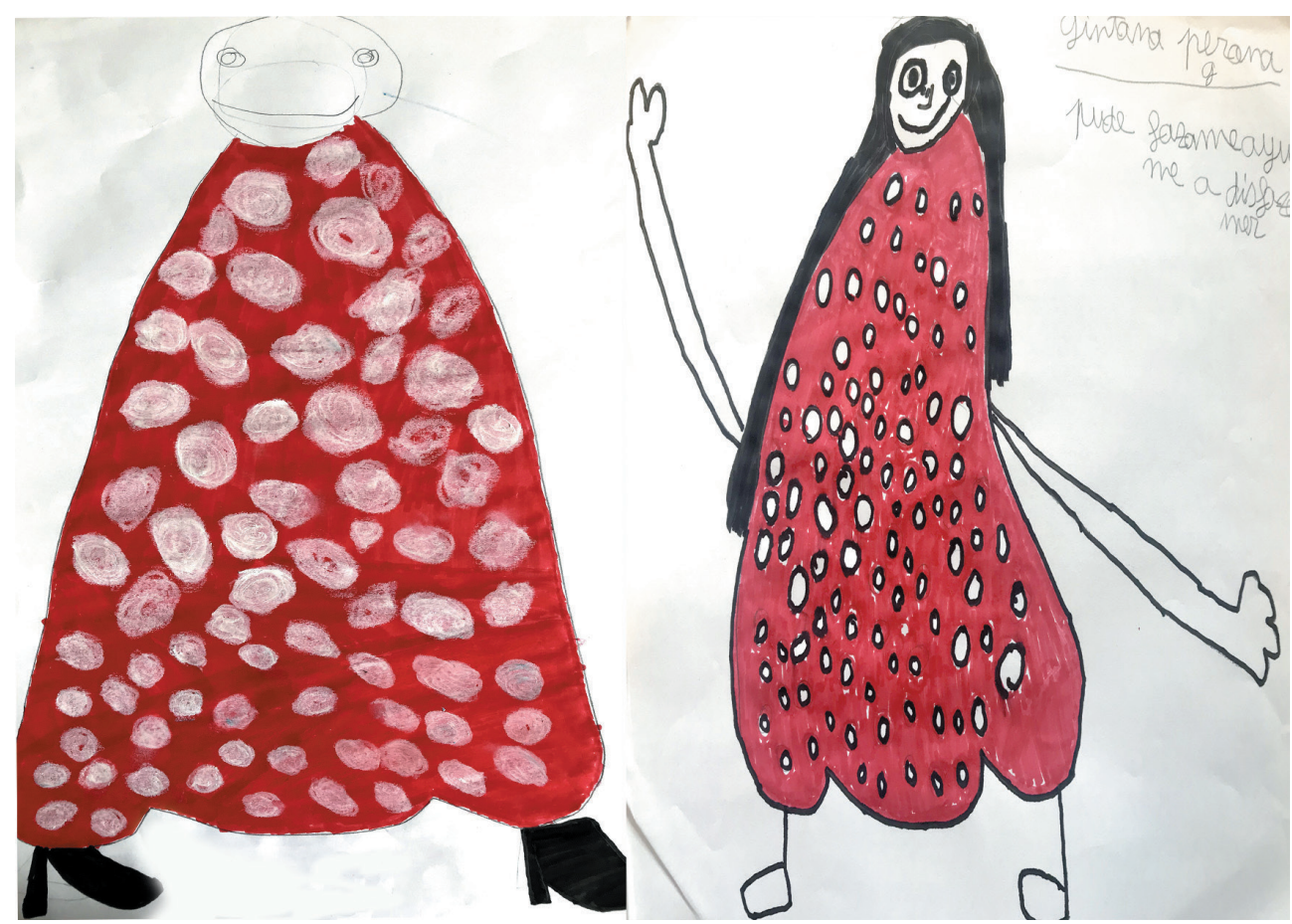

Fig. 3. Imagen de la derecha. Título: Sevillana.

Imagen de la izquierda. Título: Gitana pegona.

Fotografía de la autora 


\section{Proteger mi isla. Un lugar para vivir}

En este momento Roberto y yo llevamos unos 6 meses de trabajo. Observo que Roberto comienza a manifestar una conciencia de sí mismo a través de la imagen de la sevillana, que comenzó siendo un espectro fantasmagórico (una imagen de los otros), para encarnar una mujer mala y desafiante que sacude al otro. Entiendo que desde estas imágenes comienza a manifestar cada vez con más certeza, dentro y fuera del taller, su fantasía de ser mujer. Durante este tiempo realiza también marionetas con las que comienza a escenificar y fantasear historias: historias de princesas encerradas, hasta que de repente aparece un príncipe, y comienza a fantasear con escenas de sexualidad explicita.

Fuera del taller comienza también a fantasear con una historia en la que un chico, que tiene un estudio de fotografía, le propone hacerle fotos desnudo. Esos encuentros germinan en relaciones sexuales fantasiosas que expresa con pelos y señales a algunos profesionales del centro. La confesión del Roberto alarma a los profesionales del centro y se decide tener una reunión con los padres. En esta reunión Roberto reconoce que se había inventado esa historia para que le hicieran caso. La situación se cierra como una llamada de atención del usuario, y se decide tomar medidas en casa, limitando el acceso a películas e internet.

Esa reunión marcaría un antes y un después en las sesiones de arteterapia, tras esa reunión su actitud en el taller es muy diferente. Se muestra triste y desilusionado con el taller. Le propongo trabajar con cartones, construir en tres dimensiones.

- Quizás te apetezca tener un escenario para tus marionetas, un espacio para ellas - le propongo.

Me dice que prefiere no volver a trabajar con las marionetas, que únicamente vendría al taller a dibujar. Durante toda la sesión se mantiene en silencio y concentrado en el dibujo de un mar embravecido. (Fig. 4. Título: La piscina de la puerta principal. Dibujo con lápices de colores. Imagen de la autora). Un mar inmenso y profundo que parece invadirlo todo. Al terminar su trabajo Roberto Dice:

- Se acabaron las fantasías. He dibujado la piscina de la puerta principal, todo agua, no acaba nunca el agua. No vayas nunca a la piscina de la puerta principal. Es como un océano. Han muerto varios críos allí porque no pueden salir del agua. En todas partes, todo es agua- Expresa textualmente Roberto.

Le pregunto si ha pasado algo en estos días ya que me sorprende que no haya querido trabajar con las marionetas y ese cambio tan repentino en su proceso. Me cuenta que ha ocurrido algo muy gordo, que sus padres le han dicho que las fantasías se tienen que acabar o lo perderá todo.

- Me han castigado sin ordenador, sin música, sin películas, sin nada que me gusta. Necesito divorciarme de mis padres - Cuenta Roberto.

En las siguientes sesiones prefiere seguir únicamente dibujando en el taller. En este momento dibuja una escena en la que aparece una isla (Fig. 5). Mientras dibuja, del mismo modo que ocurría con las marionetas, comienza a contar una historia. Me 
cuenta que en esa isla vivía una princesa con sus padres, pero, de repente, aparece un barco pirata, lleno de piratas que quieren matarlos y quedarse con la isla. Los piratas cogen a los padres y los meten dentro del barco en una jaula. Me cuenta que la princesa queda, entonces, sola y escondida en la isla. Después los piratas empiezan a lanzar bombas con cañones hacía la isla. La princesa recoge una de las bombas que no explota y la lanza al barco pirata. El barco pirata explota, mueren todos: los piratas y los padres.

Me sorprende el trágico final y le pregunto qué pasará ahora con la princesa.

- Ella se queda viuda, viuda de sus padres. Ha sido un accidente, ella tenía que salvar la isla.

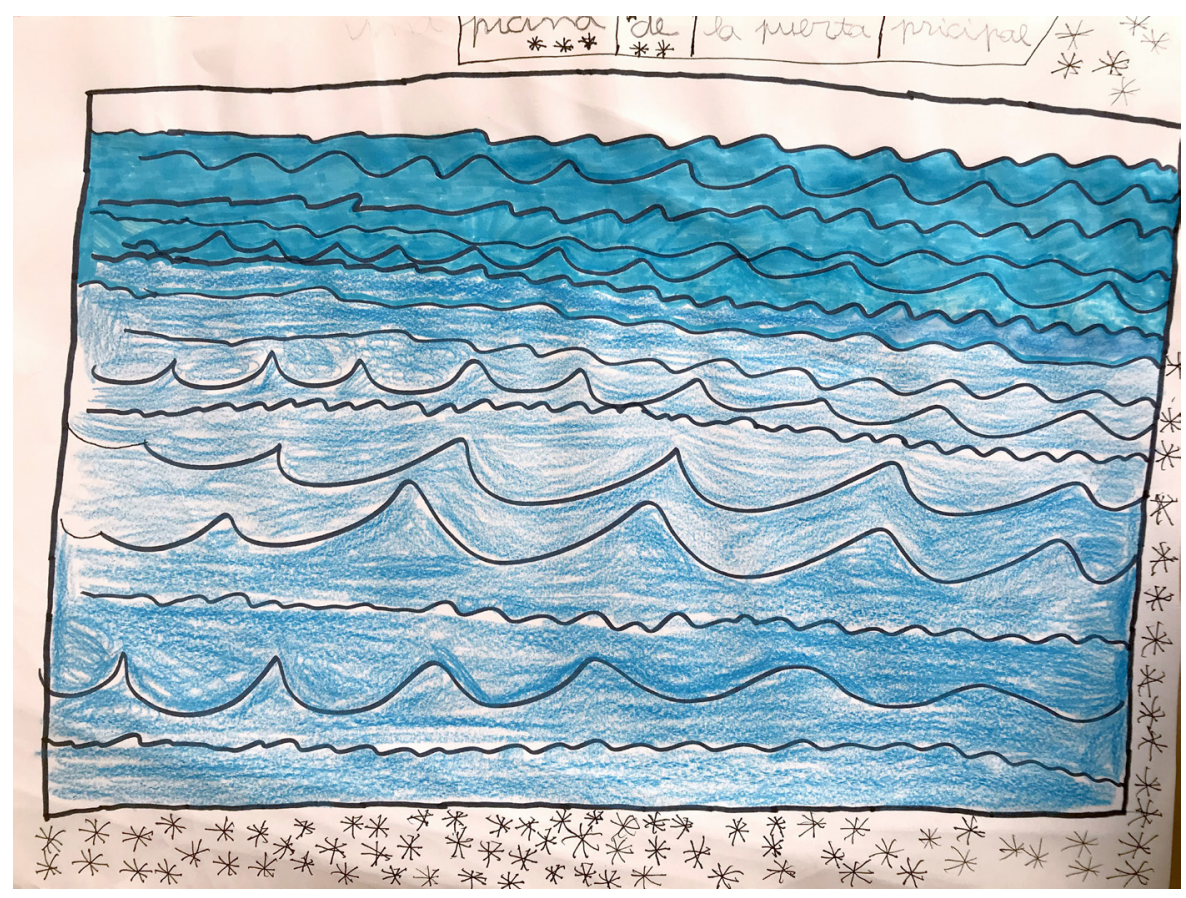

Fig. 4. Título: La piscina de la puerta principal. Dibujo con lápices de colores.

Imagen de la autora

Pienso que un final feliz habría resultado imposible, ya que no corresponde con la verdad, y es que en la historia de Roberto, los padres necesitan morir para que él pueda ser. La historia termina tristemente para los padres, pero ella consigue salvar su isla. Le devuelvo que en la sesión anterior todo era océano, y que es maravilloso saber que en medio de un océano uno puede nadar y refugiarse en una isla.

A menudo aparecían islas amenazas en las historias de Roberto. Y de estas islas entendía cada vez más lo que significaba para él $a$-islarse: viajar a su isla, encontrarse con su subjetividad, aquello que constituye y construye al sujeto. El arteterapeuta Francisco Jesús Coll se pregunta en su tesis doctoral ¿dónde vive la persona con discapacidad psíquica? y argumenta que: “el lugar donde vive el sujeto psíquico es el lugar desde 
donde se puede pensarse. Este lugar, es un lugar que siempre está suspendido, soportado o sostenido por el deseo de las personas que nos acompañan.” (Coll, 2015: 136).

Roberto sabe que debe proteger su isla, porque en ella habita todo lo que hay de él, y que la única forma de conquistar ese lugar de su subjetividad es habitándolo sólo, sobreponiéndose al dolor de la separación: viudo/a de los padres. Me di cuenta de cómo en la discapacidad, padres y tutores, invadíamos continuamente esas islas. Intentábamos quitárselas para retenerlos dentro de nuestra realidad capacitadora. Y de cómo las prohibiciones, los castigos, y la incapacidad de esos otros significantes para reconocer y respetar su isla, empujan a la persona con discapacidad, cada vez más, hacía su mundo a-islado.

Quedaba claro también en su relato, que no existen las islas aisladas, ya que siempre alguien podía llegar a ellas. Y es que el lugar de subjetividad se construye en el encuentro con el otro: en la intersubjetividad. Es justo en el espacio de la intersubjetividad, donde la persona con discapacidad se mantiene vagando sin rumbo y en un imposible equilibrio, puesto que se encuentran en un lugar donde no puede reconocerse ni en la semejanza del otro, al que se siente claramente diferente, ni en la diferencia, que se torna difícil de soportar (Coll, 2015: 135 -137). Su espacio interno es un lugar despersonalizado, de difícil referencia, donde resulta imposible o muy difícil habitar lo propio, lo más singular de sí mismo. Sin embargo Roberto podía volver a su isla a través de la creación. La actividad se convierte en un santuario donde los sentimientos y las percepciones que normalmente se ahogan en su interior pueden ser expresado y sentidos por primera vez (Krammer, 1971: 171). Proporcionándole un espacio donde poder ser: ser autor de su obra y su pensamiento.

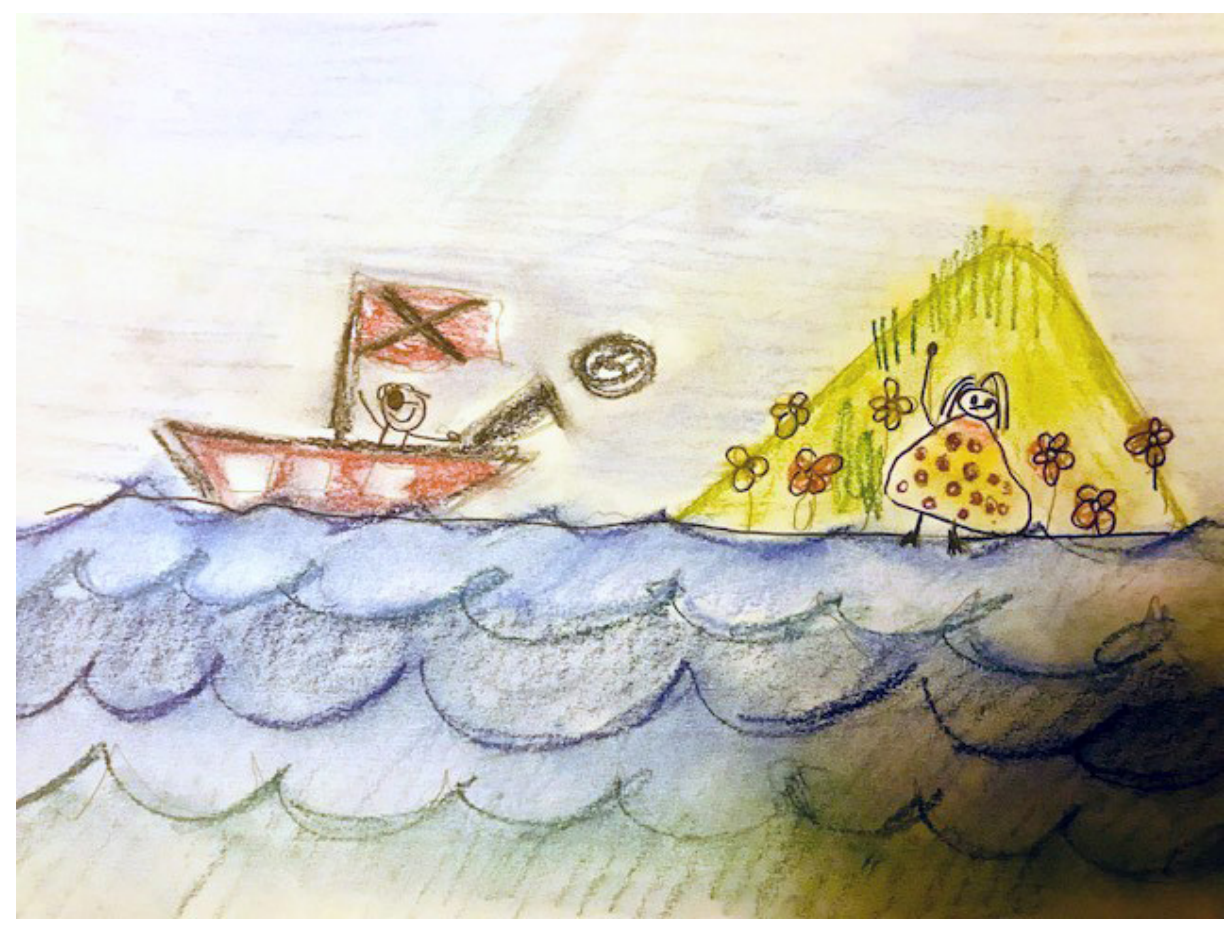

Fig. 5. Título: La isla de los piratas. Dibujo con lápiz y pastel. Imagen de la autora 


\section{Construirse un Hombre}

Desde la reunión con sus padres, Roberto rechaza sus marionetas, como si estas fueran las culpables de su castigo. Más adelante decide hacer una marioneta nueva. Expresa que, en esta ocasión, quiere hacer un hombre hecho y derecho. Trabajamos durante cuatro o cinco sesiones en la construcción de su marioneta. Le resulta de nuevo muy frustrante realizar el rostro y sobretodo el pelo al que le dedica toda una sesión. Repite continuamente que quiere que, esta vez, su marioneta sea un hombre.

A lo largo de las sesiones, pese al interés de Roberto por construirse un hombre, nos encontramos de nuevo una marioneta a la que le pone elementos femeninos: un pelo de mujer, un vestido y un chal por lo hombros (Fig. 6. Título: Un hombre hecho $y$ derecho. Marioneta de papel maché. Fotografía de la autora). Pese a que reconoce no haber realizado el hombre que esperaba, se siente muy satisfecho con su nuevo títere, le cuida, lo acaricia en el taller y peina continuamente con sus manos.

- Es precioso. Me encanta su pelo negro. Se va a llamar Fuensanta - manifiesta.

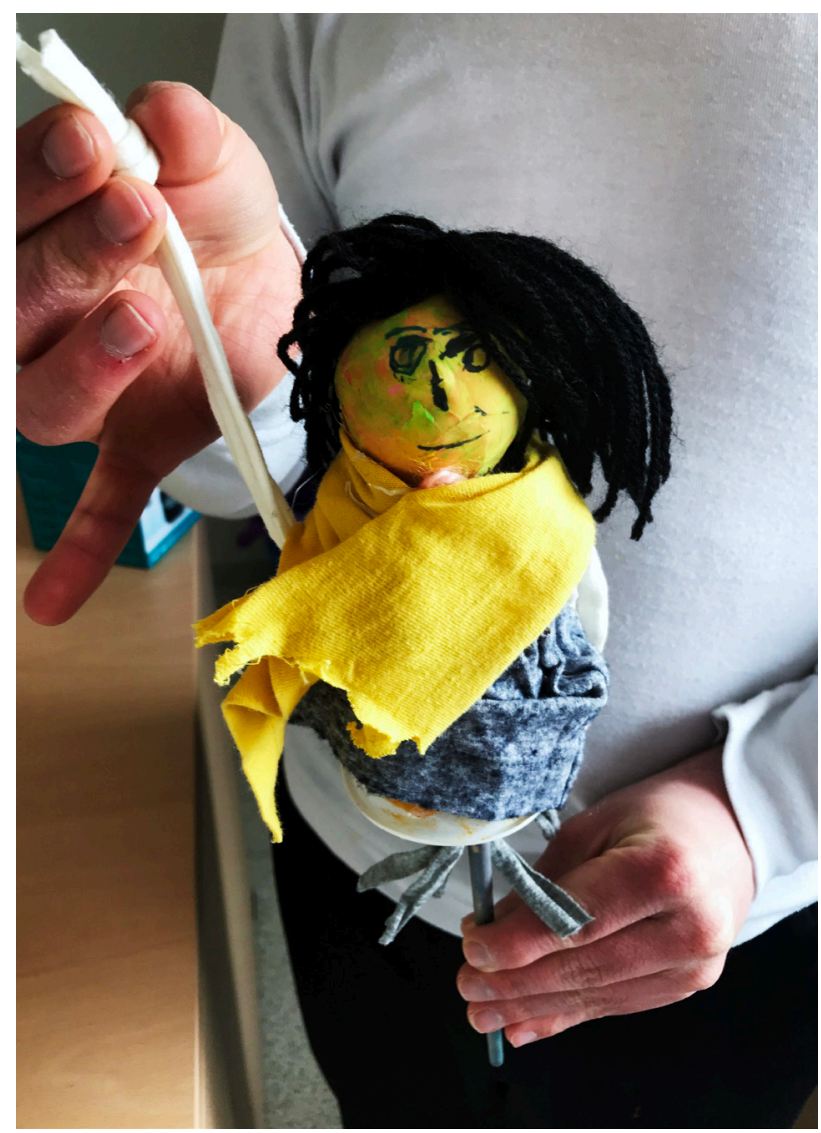

Fig. 6. Título: Un hombre hecho y derecho. Marioneta de papel maché.

Fotografía de la autora 
Una vez acabado su títere, ya puede jugar y escenificar con él. El títere como elemento de trabajo en arteterapia, va a aportar no sólo la posibilidad de escenificar, sino que además da lugar a una nueva forma de expresión verbal. Al animar al títere y ponerle voz estaremos utilizando un tipo de lenguaje diferente al utilitario, el propio de cada participante con sus ritmos, con sus silencios, con sus propias palabras y símbolos: un lenguaje interior, es lo que Martha Y. Fernández llama el lenguaje jugado, "casi en otra dimensión, cercano a la magia, que logrará darle carácter de realidad a la fantasía, a los deseos, a lo posible. (Fernández, 1995: 33). Y sería, es en este lenguaje, que posibilita el juego, en el que Roberto dice:

- Vamos compañeras, vamos a escaparnos de campamento de jovencitas. Si te cogen te lavarán el cerebro como a mí. Serás una pobrecita.

Entonces corre por el espacio escenificando una huída. Le pregunto qué ocurre. Me cuenta que Fuensanta, su títere, está en una escuela de jovencitas y que los profesores son muy malos, le quieren lavar el cerebro. Me explica textualmente:

- No le quieren lavar la cabeza, le quieren lavar el cerebro por dentro. Con un bisturi, echan el pelo para adelante y cortan con un bisturí. Echan dentro un poco de gel y de agua, frotan durante nueve minutos y después escurren con el agua. Después de eso es una cría pequeña que no sabe hacer nada. En el cerebro había manchas verdes y negras. Las manchas verdes son jaquecas, lo negro es suciedad. Por eso tenía pensamientos socios y jaquecas.

- Pensamientos sucios... ¿Qué es un pensamiento sucio? - Le pregunto.

Evita la pregunta y tras un tiempo de reflexión me responde:

- Pensaba lo que ella quería. Sus padres le castigaban sin ordenador, sin películas, sin curso de arte, sin ocio. Se lo quitaban todo.

Me dirijo a la muñeca y le pregunto:

- Y ahora, ¿En qué piensas?

- Ahora no Piensa. Es una cría pequeña. No habla y no piensa. - Me contesta Roberto

El pensamiento y la identidad subjetiva serían la misma cosa. Aquel que asalta mi espacio propio, estaría asaltando mi pensamiento. Si hay algo, que pertenece al sujeto, por encima de cualquier cosa, sería su propio pensamiento. Ser tiene que ver, sobretodo, con una cierta forma de sentirse autor de los propios pensamientos, y la creación parece el lugar idóneo para que Roberto pueda ser. A través de su último títere, Roberto se apropia definitivamente de su pensamiento, manifiesta que existe algo de horroroso en él: pensamientos sucios, algo hostil que no puede reconocer en sí mismo. Sin embargo, huye para proteger lo que su suyo: sus pensamientos: sus fantasías, de aquellos que intentan arrebatárselas. 


\section{Conclusiones}

Roberto no pudo construirse un hombre, a pesar de sus esfuerzos por complacer el deseo del otro. Seguimos trabajando juntos en la compleja búsqueda de esa identidad propia, que le permita adueñarse definitivamente de un género. Sin embargo, aunque el camino es difícil, considero que este momento ya habíamos conquistado varios territorios:

La falda de sevillana, fue envolviendo progresivamente al sujeto psíquico, pasando de aquel ser fantasmagórico e impropio, que constituía la construcción de una imagen de los otros (Un falso Self), hacía una imagen propia, un ser que actúa, que pega, que además puede ser mala y pegona, según afirma Roberto. Tener una imagen le permitía la posibilidad de nombrar, de actuar, de tener pensamientos propios, que debían ser protegidos, aunque estuvieran sucios.

Las fantasías que llevaron a Roberto a su castigo, constituyen la conquista de su ser creativo: recuperar la fantasía como la solución mágica de la omnipotencia infantil, recuperar el espacio transicional (espacio ficcional), el espacio de juego, donde es posible vivir en la fantasía la angustia que comporta la aceptación de la realidad. El juego, la simbolización a través de la creatividad, permitía a Roberto la búsqueda de su verdadero self, ya que, trayendo de nuevo las palabras de Donald Winnicott: "En el juego, y sólo en el juego, puede el niño o el adulto crear, y usar toda su personalidad. El individuo descubre su self, solo cuando se muestra creador" (1971: 80). El yo creativo es aquel que puede fantasear, aquel que vive inmerso en un mundo entre lo externo y lo interno, con unas leyes propias.

Aquel mundo de leyes propias resultó ser una isla. La isla supuso la representación de su subjetividad, el lugar en que uno puede pensarse, el lugar que uno debe habitar para encontrarse consigo mismo. Roberto sabía que únicamente sólo, separándose por fin de la relación sentimental con los padres (divorciado y viudo de sus padres), podría habitar ese espacio propio de la subjetividad.

A través de un juego de contenidos inconsciente Roberto ha transitado lugares propios, ha establecido puentes de acceso a lo subjetivo. Ahí, en aquello que crea, entre lo interno y lo externo, puede edificar su pensamiento (propio o sucio). La creación permitió a Roberto encontrase con algo que le representa: un espacio de representación subjetiva, en el cual encontró un modo propio de ser y de presentarse a los otros.

\section{Referencias bibliográficas:}

Coll Espinosa, F. (2015).Tesis Doctoral: Aplicaciones del Arteterapia en el desarrollo de Capacidades asociativas y Cognitivas en personas con discapacidad psíquica. Ed. Universidad de Murcia. Murcia.

Dalley, T \& Case, C (1992) The Handbook of Art Therapy, Ed. Second edition. London Fernández, M. Y. (1995) Títeres en la clínica o el regreso de la preciosa. Ed. Lugar editorial S.A. Buenos Aires.

Freud, S. (1901-1905) Tres ensayos sobre la Teoría sexual. En: Obras completas. Tomo VII. Ed. Amorrortu Editores. (Primera edición en castellano, 1976.) Buenos Aires.

Krammer, E (1971) Art as Therapy with children. Ed. Schocken Books. New York.

Kristeva, J. (1989) Poderes de Perversión (ensayo sobre Louis-Ferdinand Céline). Ed. Siglo XXI editors. Buenos Aires. 
López Mondejar. L. (2009) El Factor Munchausen. Psicoanálisis y creatividad. Ed. Cendeac. Murcia

Montobio, E. (1995). La dificil identidad. El falso Yo en la persona con discapacidad psíquica. Una hipótesis teórica según el pensamiento de Bion. Ed. Masson. Fundación catalana síndrome de Down. Barcelona.

Winnicott D. W (1960) La contratransferencia. En El proceso de maduración y el ambiente facilitador (pp. 207-216) Barcelona: Paidos, (1992)

Winnicott D.W. (1962) La integración del Ego en el Desarrollo del niño. En: El Proceso de maduración de niño. Barcelona: Ed. Laia (1975)

Winnicott, D.W. (1963) Procesos de maduración y el ambiente facilitador. Estudios para una teoría del desarrollo emocional. Barcelona: Ed. Paidós (1999)

Winnicott D.W. (1971). Realidad y Juego. Barcelona: Ed. Gedisa. (1997) 